\title{
Electrophysiological status of sural nerves in type 2 diabetes mellitus patients before symptomatic peripheral neuropathy
}

\begin{abstract}
Introduction. Neuropathies in type 2 diabetes mellitus (T2DM) patients are well known. However, electrophysiological changes in their peripheral nerves, particularly before overt peripheral neuropathy have received much less attention. Hence, we aimed to study the electrophysiological status of bilateral sural nerves in T2DM patients who do not show symptoms and signs of peripheral neuropathy.

Material and methods. We selected 35 T2DM male patients and 35 age- and sex-matched control subjects without any clinical evidence of peripheral neuropathy and infectious, systemic, metabolic, and neuropsychiatric illnesses after informed written consent. Nerve conduction study (NCS) of bilateral sural nerves of both the groups was done at the lab temperature of $26 \pm 2^{\circ} \mathrm{C}$ by antidromic method of stimulation using standard methods. Their latency, conduction velocity, amplitude, and duration of bilateral sural sensory nerve action potentials (SNAPs) were measured and compared.
\end{abstract}

Address for correspondence:

Dr. Raju Panta, MD

Assistant Professor, Physiology

Trinity School of Medicine

Ratho Mill, Kingstown

St. Vincent and the Grenadines

Phone: +1 7845280842

e-mail: tsomdesk.rp@gmail.com

Clinical Diabetology 2017, 6, 4, 126-130

DOI: $10.5603 /$ DK.2017.0021

Received: 25.08.2017

Accepted: 08.10.2017
Results. T2DM patients had reduced amplitudes of bilateral sural SNAPs compared to control subjects [left (12.46 \pm 3.77) $\mu \mathrm{V}$ vs. (16.42 \pm 4.58$) \mu \mathrm{V}, \mathrm{p}=0.000$; right (11.96 \pm 4.45$) \mu \mathrm{V} v s .(16.62 \pm 6.20) \mu \mathrm{V}, \mathrm{p}=0.001]$ though they were above the normal cut-off value of $\geq 4 \mu \mathrm{V}$. T2DM patients showed prolonged durations of bilateral sural SNAPs compared to the control subjects [left $(1.99 \pm 0.38) \mathrm{ms} v$ s. $(1.67 \pm 0.27) \mathrm{ms}, \mathrm{p}=0.000$; right $(1.92 \pm 0.47) \mathrm{ms}$ vs. $(1.55 \pm 0.33) \mathrm{ms}, \mathrm{p}=0.000]$. Conclusion. Reduced amplitudes and prolonged durations of bilateral sural SNAPs are the electrophysiological alterations, suggestive of peripheral neuropathy, in T2DM patients that appear before they show clinical symptoms and signs of peripheral neuropathy. (Clin Diabetol 2017; 6, 4: 126-130)

Key words: diabetes mellitus, peripheral neuropathy, nerve conduction study, sural SNAP, axonal loss

\section{Introduction}

Diabetic neuropathy can involve any peripheral nerve and is one of the major causes of morbidity among diabetes patients. Distal symmetric polyneuropathy is the most common form of diabetic neuropathy. The most frequent presentation includes distal sensory loss, though numbness, tingling, sharpness, or burning sensations that begin in the feet and spreads proximally. However, up to $50 \%$ of patients do not have symptoms of neuropathy [1]. Some studies have reported the evidences of central neuropathy in T2DM patients, though the patients do not have symptoms of central nervous system (CNS) impairment [2-5]. 
Peripheral neuropathies are important complications of diabetes mellitus associated with sensory loss, pain, and may be weakness [6]. Electrophysiological investigations are sensitive in determining peripheral and central neuropathy in diabetes patients. Nerve conduction study (NCS) and electromyography (EMG) are frequently used to diagnose the disorders of peripheral nervous system (PNS) [7]. In practice, these electrophysiologic studies serve as an extension of the clinical examination. NCS is essential in the diagnosis of focal neuropathies and diffuse polyneuropathies [8]. These studies are also an accurate and non-invasive method of evaluating the status of the peripheral nerves [9].

Sural nerve (short saphenous nerve) is the only pure sensory nerve in the leg, which is tested routinely. It supplies the branches to the skin on the back of the leg and then continues as lateral dorsal cutaneous nerve along the outside of the foot and little toe. Routine NCS includes motor nerve conduction velocity (NCV), sensory nerve action potential (SNAP), F-wave study, and $\mathrm{H}$-reflex. Although the NCS complement one another, each yields different information. Diabetic neuropathy that most frequently present with distal sensory loss is one of the most common indications for NCS [10].

Sensory NCS is integral of any electrophysiological evaluation because they are more sensitive than motor NCS in detection of early or mild disorders [11]. A compound potential that represents the summation of all the individual sensory fiber action potentials is the sensory nerve action potential (SNAP). SNAPs are usually biphasic or triphasic potentials [12].

Abnormalities within the PNS in T2DM patients are well documented. However, the electrophysiological changes in the PNS, particularly before the development of the symptoms in them, have received much less attention. Hence, in this study, we studied electrophysiological status of bilateral sural nerves in T2DM patients who do not have clinical evidence of peripheral neuropathy and subjects with normal sural SNAPs were included as the study population.

\section{Materials and methods}

This was a comparative cross-sectional study done at B.P. Koirala Institute of Health Sciences (BPKIHS), Nepal with approval from the ethics committee. Thirtyfive T2DM male patients and 35 age- and sex-matched control subjects were selected using a convenience sampling technique based on the inclusion and exclusion criteria. The T2DM patients were newly diagnosed or follow-up cases on oral hypoglycemic drugs, including sulphonylureas and metformin. The control subjects did not have symptoms of any disease, were normal on clinical examination, were not on any medication, and had normal fasting plasma glucose (FPG). Both the groups had no clinical evidence of infectious, systemic, metabolic, and neuropsychiatric illnesses. The subjects in both the groups had no symptoms of peripheral neuropathy. The subjects were further examined clinically for the intactness of sensations by testing for pain, light touch, position, stereognosia, graphesthesia, and extinction. The subjects with symptoms of peripheral neuropathy and abnormality in sensory examinations were excluded from the study.

The participants were familiarized with the laboratory setting and the study design. All the participants were informed of the potential risks and recording procedures, and informed written consent was obtained. They were interviewed using standardized questionnaires for their medical history. Their detailed medical history, clinical examinations, and health status were documented using standard case history sheets. The recent reports on FPG, postprandial glucose (PPG), and glycated hemoglobin $\left(\mathrm{HbA}_{1 \mathrm{c}}\right)$ of the T2DM patients were noted. The FPG of control subjects was assessed and documented. The weight, height, systolic blood pressure (SBP), diastolic blood pressure (DBP), respiratory rate (RR), heart rate (HR), and arterial oxygen saturation $\left(\mathrm{SaO}_{2} \%\right)$ of both the T2DM patients and control subjects were measured using standard tools and methods. Their body mass index (BMI, $\mathrm{kg} / \mathrm{m}^{2}$ ) was calculated. The duration of diabetes in T2DM patients could not be reported because most of the patients included in the study were diagnosed of T2DM long after they started having features of DM. However, we reported the duration of diagnosis of DM in T2DM patients in years, though it was not possible to report the time duration precisely.

\section{Sensory nerve conduction recording}

The temperature of the laboratory was maintained at $26 \pm 2{ }^{\circ} \mathrm{C}$. The subjects were advised to relax and their comfort was maintained before and during the recording procedures. The equipment used was a Digital Nihon Kohden machine (NM-4205, H636, Japan) and its accessories.

Each subject was asked to relax the limb during recording. Antidromic method of stimulation was followed for studying sural NCS where the stimulation site was at the posterior lateral calf and the recording site was at the posterior ankle. Skinpure (skin purifier) was applied to clean the recording electrode site to reduce the skin impedance. A pair of recording electrodes was placed in line over the nerve at an inter-electrode distance of 3-4 cm, with the active recording electrode towards the side of the stimulating electrodes. Ground 
Table 1. Stimulus parameters for sensory nerve conduction studies [10]

\begin{tabular}{ll}
\hline Parameter & $\begin{array}{l}\text { Sensory nerve } \\
\text { conduction studies }\end{array}$ \\
\hline Gain & $20 \mu \mathrm{V}$ per division \\
Time base & $1 \mathrm{~ms}$ per division \\
Low-frequency filter & $10 \mathrm{~Hz}$ \\
High-frequency filter & $32 \mathrm{kHz}$ \\
Stimulus duration & $0.1 \mathrm{~ms}$ \\
\hline
\end{tabular}

Table 2. Normal values for sural sensory nerve conduction study [10]

\begin{tabular}{llll}
\hline Nerve & Onset latency & $\begin{array}{l}\text { Nerve con- } \\
\text { duction velocity }\end{array}$ & Amplitude \\
\hline Sural & $\leq 4.2 \mathrm{~ms}$ at $14 \mathrm{~cm}$ & $\geq 42 \mathrm{~m} / \mathrm{sec}$ & $\geq 4 \mu \mathrm{V}$
\end{tabular}

electrode was placed between the recording and stimulating electrodes. Surface stimulating electrode was used. The stimulating electrode was placed clearly on the sensory portion of nerve facing its cathode towards the recording electrodes.

Most sensory responses are very small (usually in the range of $1-50 \mu \mathrm{V}$ ). Hence, for sensory NCS, the gain is usually set at $10-20 \mu \mathrm{V}$ per division as provided in the machine [10]. Stimulation parameters for sensory NCS as given in Table 1 were used.

An electrical pulse of 15 to $30 \mathrm{~mA}$ in the current range and 100 or $200 \mu$ secs in duration was given to achieve supramaximal stimulation. The current was slowly increased from a baseline of $0 \mathrm{~mA}$ by $3-5 \mathrm{~mA}$, until the recorded sensory nerve action potential was maximized. Each nerve was stimulated 20 times with supramaximal stimuli and the average was recorded. For each stimulation site the onset latency, amplitude, duration, and conduction velocity were measured. The normal cutoff values given in Table 2 were considered for sural SNAP. The T2DM patients with abnormal sural SNAPs were excluded from the study.

\section{Statistical analysis}

The data obtained were exported to the Statistical Package for the Social Sciences (SPSS version 24) and were tested for normal distribution. The data of age, weight, height, BMI, SBP, DBP, HR, RR, $\mathrm{SaO}_{2}$, blood sugar profile, and variables of bilateral sural SNAPs were normally distributed and expressed in terms of mean \pm standard deviation. The unpaired t-test was used for comparison of all the variables between T2DM patients and control subjects. A p value of $<0.05$ was considered statistically significant.
Table 3. Anthropometric, FPG, and cardio-respiratory variables of T2DM and controls

\begin{tabular}{lccc}
\hline Variables & \multicolumn{2}{c}{ Mean \pm SD } & p value \\
\cline { 2 - 3 } & T2DM & Control subjects & \\
& $(\mathbf{n}=35)$ & $(\mathbf{n}=35)$ & \\
\hline Age (years) & $53.67 \pm 2.74$ & $52.64 \pm 3.25$ & 0.156 \\
Weight [kg] & $63.75 \pm 4.52$ & $64.89 \pm 4.72$ & 0.307 \\
Height [cm] & $165.30 \pm 6.07$ & $166.99 \pm 6.78$ & 0.276 \\
BMI [kg/m²] & $23.36 \pm 1.63$ & $23.29 \pm 1.43$ & 0.846 \\
FPG [mmol/L] & $9.26 \pm 2.67$ & $5.05 \pm 0.58$ & 0.000 \\
SBP [mm Hg] & $118.80 \pm 5.92$ & $120.27 \pm 5.72$ & 0.293 \\
DBP [mm Hg] & $74.74 \pm 4.80$ & $74.06 \pm 4.40$ & 0.535 \\
HR [beats/min] & $79.46 \pm 5.52$ & $79.69 \pm 6.92$ & 0.881 \\
RR [breaths/min] & $13.58 \pm 1.60$ & $14.17 \pm 2.15$ & 0.199 \\
SaO ${ }_{2}(\%)$ & $96.96 \pm 1.44$ & $97.22 \pm 1.28$ & 0.428 \\
\hline
\end{tabular}

\section{Results}

There were no statistically significant differences in age, weight, height, BMI, SBP, DBP, $\mathrm{HR}$, RR, and $\mathrm{SaO}_{2}$ among the groups. The mean FPG of control subjects was significantly less $(p=0.000)$ compared to T2DM patients (Tab. 3). The PPG and $\mathrm{HbA}_{1} \mathrm{C}$ of T2DM patients were $13.42 \pm 4.84 \mathrm{mmol} / \mathrm{L}$ and $6.79 \pm 0.83 \%$ respectively. The duration of diagnosis of DM in T2DM patients was $5.43 \pm 2.56$ years.

Latency, conduction velocity, amplitude, and duration of bilateral sural nerves were compared between T2DM patients and control subjects. The amplitudes of bilateral sural SNAPs were reduced $(p<0.05)$ in T2DM patients compared to control subjects (Table 4) though they were above the normal cutoff values of $\geq 4 \mu \mathrm{V}$ (Tab. 2). In addition, there were prolonged durations of bilateral sural SNAPs in T2DM patients compared to control subjects (Tab. 4).

\section{Discussion}

The aim of this study was to assess electrophysiological status of bilateral sural nerves in T2DM patients before they show the symptoms of peripheral neuropathy. Our study revealed reduced amplitudes and prolonged durations of bilateral sural SNAPs in T2DM patients compared to control subjects.

Previous studies [12-14] have stated that the amplitude of the SNAP reflects the number of sensory nerve axons and reduced SNAP amplitude is the primary abnormality associated with axonal loss. Comparing the amplitude of a potential with a normal control value is one of the best ways to assess the amount of axonal loss. One of the typical patterns associated with axonal loss is reduced amplitudes with preserved latencies and conduction velocities. Sensory amplitudes often are low in demyelinating lesions [12]. 
Table 4. Comparison of sural SNAP variables between T2DM patients and control subjects

\begin{tabular}{llccc}
\hline \multirow{2}{*}{ Variables } & Side & \multicolumn{2}{c}{ Mean \pm SD } & p value \\
\cline { 3 - 4 } & & T2DM $(\mathbf{n}=35)$ & Control subjects $(\mathbf{n}=35)$ & 0.766 \\
\hline \multirow{2}{*}{ Latency $[\mathrm{ms}]$} & Left & $2.42 \pm 0.36$ & $2.39 \pm 0.45$ & 0.311 \\
& Right & $2.48 \pm 0.37$ & $2.40 \pm 0.32$ & 0.603 \\
Conduction velocity $[\mathrm{m} / \mathrm{s}]$ & Left & $56.30 \pm 5.09$ & $57.33 \pm 10.41$ & 0.632 \\
& Right & $58.06 \pm 9.30$ & $59.08 \pm 8.40$ & $\mathbf{0 . 0 0 0}$ \\
Amplitude $[\mu \mathrm{V}]$ & Left & $12.46 \pm 3.77$ & $16.42 \pm 4.58$ & $\mathbf{0 . 0 0 1}$ \\
& Right & $11.96 \pm 4.45$ & $16.62 \pm 6.20$ & $\mathbf{0 . 0 0 0}$ \\
Duration $[\mathrm{ms}]$ & Left & $1.99 \pm 0.38$ & $1.67 \pm 0.27$ & $\mathbf{0 . 0 0 0}$ \\
\hline
\end{tabular}

These studies suggest the idea that the reduced amplitudes of bilateral sural SNAPs that we found in our study in T2DM patients compared to control subjects could be due to axonal loss, which often occurs in demyelinating disease.

In our study, we found prolonged durations of bilateral sural SNAPs in T2DM patients compared to the control subjects. The prolongation of sural SNAP duration is seen in polyneuropathies. However, the sural SNAP duration does not contribute to classifying polyneuropathies as axonal and demyelinating [15].

Sural nerve biopsies in diabetic patients with severe progressive neuropathy despite good blood glucose control have shown small vessel disease within the nerve [16]. Both ischemia and hypoxia are present in diabetic nerve in animals [17]. Impaired glucose tolerance (IGT) is a transitional state before diabetes and the dorsal sural nerve latencies are important for early detection of neuropathy. Sural nerve studies should be of value to determine neuropathy in IGT patients [18].

The amplitude of SNAP tends to be slightly higher in children due to lower skin impedance. After 60 years of age, NCV begins to slow slightly [10]. Aging deeply influences several morphological and functional features of the PNS, affects functions, and electrophysiological properties of the PNS, including reduced NCV, muscle strength, sensory discrimination, autonomic responses, and endoneural blood flow [19]. In our study, the mean age of T2DM patients is $53.67 \pm 2.74$ years, which suggests that the age of the patients did not influence significantly the result of our study. The effect of aging (60 years) may be seen in our population earlier than in western countries.

The increased BMI and lower sensory/mixed nerve amplitudes should be taken into account in clinical practice [20]. The NCV correlates more strongly with the height than with the age [21]. Height shows a significant correlation with most of the motor nerve conduction parameters and with a few sensory nerves [22]. However, in our study, the weight, height, and BMI were comparable between the groups.

We conducted our study in male population only, which avoided the variation in NCS due to sex differences. The SNAP latencies and duration are longer in males, whereas amplitude is higher in females. In addition, males have higher compound muscle action potential amplitude, longer latencies, and duration than the females [23]. Thus, similar study on female population is suggested.

Sensory nerve response duration increases linearly with decline in skin temperature. The conduction velocity for the fastest and slowest conducting sensory fibers increases non-linearly with an increase in skin temperature beyond the temperature range of $17-37^{\circ} \mathrm{C}$ [24]. In our study, we had maintained the temperature of the laboratory at $26 \pm 2^{\circ} \mathrm{C}$, which prevented variation in the NCS due to temperature.

Abnormality in NCS in diabetic neuropathy appears earlier than clinical symptoms and signs without small fiber neuropathy. Therefore, NCS is important in the early detection of diabetic neuropathy [25].

We found reduced amplitudes and prolonged durations of bilateral sural SNAPs in T2DM patients compared to control subjects, although T2DM patients did not show overt peripheral neuropathy. Hence, we concluded that electrophysiological alterations suggestive of peripheral neuropathy occur in patients with T2DM before they show any clinical features of peripheral neuropathy. Early detection of peripheral neuropathy in T2DM patients enables clinicians to help prevent long-term complications of diabetes mellitus such as foot ulcers and amputations.

Our study did not include more than one test modalities and could not evaluate the status of all the vulnerable sensory, motor, and mixed peripheral nerves. Future studies should compare nerve conduction vari- 
ables of the other vulnerable sensory, motor, and mixed peripheral nerves along with sural nerve (including evaluation of small fiber neuropathy, e.g. fibers for temperature sensation) among diabetic patients with symptomatic peripheral neuropathy, diabetic patients without symptoms of peripheral neuropathy, and control subjects.

\section{Acknowledgments}

The authors are thankful to the faculty members, laboratory technicians, and colleagues for their contributions and support in this study. The authors also thankfully acknowledge all the patients, their relatives, and healthy individuals for their active participation in the study.

\section{Statement of competing interest}

The authors report no competing interest. This research did not receive any specific grant from any funding agency in the public, commercial, or not-forprofit sector. However, the resources required for the study were made available by the institute for routine postgraduate thesis.

\section{REFERENCES}

1. Powers AC, Kasper DL, Fauci AS, Hauser SL, Longo DL, Jameson JL, Loscalzo J. Diabetes Mellitus: Comlications. In: Harrison's Princiles of Internal Medicine. McGraw-Hill, New York 2015: 2422-2430.

2. Biessels GJ, Kappelle AC, Bravenboer B, et al. Cerebral function in diabetes mellitus. Diabetologia. 1994; 37(7): 643-650, doi: 10.1007/bf00417687, indexed in Pubmed: 7958534.

3. Cox DJ, Kovatchev BP, Gonder-Frederick LA, et al. Relationships between hyperglycemia and cognitive performance among adults with type 1 and type 2 diabetes. Diabetes Care. 2005; 28(1): 71-77, doi: 10.2337/diacare.28.1.71, indexed in Pubmed: 15616236.

4. Panta R, Khadka D, Thakur D, et al. Which Occurs First in Patients with Type 2 Diabetes Mellitus? Central or Peripheral Neuropathy. Int Arch BioMed Clin Res. 2016; 2(2): 73-78, doi: 10.21276/ /iabcr.2016.2.2.16.

5. Panta R, Paudel B, Limbu N, et al. Electroencephalographic changes in type 2 diabetes mellitus during hyperventilation and post-hyperventilation. Int J Adv Res. 2017; 5(4): 809-815, doi: 10.21474/ijar01/3879

6. Zochdne DW. Peripheral nerve disease. In: Zochdne DW. ed. Evidence based Diabetes Care. BC Decker, Hamilton 2001: 466-487.

7. Kodl CT, Seaquist ER. Cognitive dysfunction and diabetes mellitus. Endocr Rev. 2008; 29(4): 494-511, doi: 10.1210/er.2007-0034, indexed in Pubmed: 18436709.

8. Awang MS, Abdullah JM, Abdullah MR, et al. Nerve conduction study of healthy Asian Malays: the influence of age on median, ulnar, and sural nerves. Med Sci Monit. 2007; 13(7): CR330-CR332, indexed in Pubmed: 17599028.
9. García-García A, Calleja-Fernández J. [Neurophysiology of the development and maturation of the peripheral nervous system]. Rev Neurol. 2004; 38(1): 79-83, indexed in Pubmed: 14730498.

10. Misulis KE, Head TC. Basic principles of nerve conduction study and electromyography. In: Misulis KE, Head TC. ed. Essentials of clinical neurophysiology. Butterworth-Heinemann, Burlington 2003: 127-160.

11. Blando AV. Lower extremity sensory nerve conduction studies. Phys Med Rehabil Clin N Am. 1998; 9(4): 853-870.

12. Preston DC, Shairo BE. Basic nerve conduction studies. In: Preston DC, Shairo BE. ed. Electromyography and neuromuscular disorders. Elsevier Saunders, New York 2013: 19-35.

13. Chung T, Prasad K, Lloyd TE. Peripheral neuropathy: clinical and electrophysiological considerations. Neuroimaging Clin N Am. 2014; 24(1): 49-65, doi: 10.1016/j.nic.2013.03.023, indexed in Pubmed: 24210312.

14. Rubin DI, Daube JR. Clinical Neurohysiology. In: Rubin DI, Daube JR. ed. Alication of Clinical Neurohysiology - Assessing Periheral Neuromuscular Conditions. Oxford University Press, New York 2016: 502-534.

15. Rasmussen RH, Fuglsang-Frederiksen A, Tankisi H. ID 257 - The utility of the duration of sural nerve sensory action potential in classification of polyneuropathies. Clin Neurophysiol. 2016; 127(3): e130, doi: 10.1016/j.clinph.2015.11.441.

16. Timperley WR, Boulton AJ, Davies-Jones GA, et al. Small vessel disease in progressive diabetic neuropathy associated with good metabolic control. J Clin Pathol. 1985; 38(9): 1030-1038, doi: 10.1136/jcp.38.9.1030, indexed in Pubmed: 4044873.

17. Tuck RR, Schmelzer JD, Low PA. Endoneurial blood flow and oxygen tension in the sciatic nerves of rats with experimental diabetic neuropathy. Brain. 1984; 107 (Pt 3): 935-950, doi: 10.1093/ /brain/107.3.935, indexed in Pubmed: 6478183.

18. Koçer A, Domaç FM, Boylu E, et al. A comparison of sural nerve conduction studies in patients with impaired oral glucose tolerance test. Acta Neurol Scand. 2007; 116(6): 399-405, doi: 10.1111/j.1600-0404.2007.00886.x, indexed in Pubmed: 17986099.

19. Verdú E, Ceballos D, Vilches JJ, et al. Influence of aging on peripheral nerve function and regeneration. J Peripher Nerv Syst. 2000; 5(4): 191-208, doi: 10.1111/j.1529-8027.2000.00026.x, indexed in Pubmed: 11151980.

20. Buschbacher RM. Body mass index effect on common nerve conduction study measurements. Muscle Nerve. 1998; 21(11): 1398-1404, doi: 10.1002/(sici)1097-4598(199811)21:11<1398::aidmus6>3.0.co;2-4, indexed in Pubmed: 9771662.

21. Rivner MH, Swift TR, Malik K. Influence of age and height on nerve conduction. Muscle Nerve. 2002; 26(3): 428-429.

22. Thakur D, Jha S, Pandey NK, et al. Influence of height on nerve conduction study parameters of the peripheral nerves. J Clin Diagn Res. 2011; 5(2): 260-263.

23. Thakur D, Paudel BH, Bajaj BK, et al. Nerve Conduction Study in Healthy Individuals: a Gender Based Study. Health Renaissance. 2010; 8(3): 169-175, doi: 10.3126/hren.v8i3.4210.

24. Todnem K, Knudsen G, Riise T, et al. The non-linear relationship between nerve conduction velocity and skin temperature. J Neurol Neurosurg Psychiatry. 1989; 52(4): 497-501, doi: 10.1136/ /jnnp.52.4.497, indexed in Pubmed: 2738592.

25. Jin HY, Park TS. Can nerve conduction studies detect earlier and predict clinical diabetic neuropathy? J Diabetes Investig. 2015; 6(1): 18-20, doi: 10.1111/jdi.12236, indexed in Pubmed: 25621128. 